\title{
Prenatal Dexamethasone Treatment Improves Survival of Newborn Rats during Prolonged High $\mathrm{O}_{2}$ Exposure
}

\author{
LEE FRANK \\ Pulmonary Research Center, University of Miami School of Medicine, Miami, Florida 33101
}

\begin{abstract}
Prenatal dexamethasone (DEX) treatment is known to accelerate the maturation of both the surfactant system and the fetal lung antioxidant enzyme (AOE) system (Frank L, Lewis P, Sosenko IRS: Pediatrics 75:569574,1985 ). Because of this stimulatory effect of prenatal DEX on the normal late gestational development of the AOE system, we questioned whether this treatment might have a salutary effect on the ability of the newborn rat to tolerate early and prolonged exposure to hyperoxia, inasmuch as the AOE are the primary lung defensive system against high $\mathrm{O}_{2}$ challenge. In nine experiments with term newborn rats in $>95 \% \mathrm{O}_{2}$, the composite percentage of survival was significantly greater in the prenatal DEX pups at all time periods in hyperoxia from $7 \mathrm{~d}$ [control pups, 67 of $94(71 \%)$; prenatal DEX, 96 of $99(97 \%)$ to $14 \mathrm{~d}$ [controls, 10 of $32(31 \%)$; prenatal DEX, 18 of $33(55 \%)$ ] $(p<0.01)$. In addition to survival per se, the prenatal DEX pups showed significantly decreased lung wet weight/dry weight ratios, pathologic evidence of pulmonary edema, and lung conjugated dienes versus the $\mathrm{O}_{2}$ control newborn group. Of the many comparative parameters examined, the major difference found between the two groups was in the pulmonary $A O E$ responses to hyperoxia. By $2 \mathrm{~d}$ in hyperoxia, the prenatal DEX rat pups showed significantly elevated superoxide dismutase, catalase, and glutathione peroxidase activities compared to air control pups, and at 4 and $7 \mathrm{~d}$ in $\mathrm{O}_{2}$ the $\mathrm{AOE}$ levels were consistently greater in the DEX group than the AOE responses in the control $\mathrm{O}_{2}$ pups. The more rapid and more pronounced AOE response to hyperoxic challenge may help to explain the substantial protective effect of prenatal DEX versus newborn $\mathrm{O}_{2}$ toxicity. (Pediatr Res 32: 215-221, 1992)
\end{abstract}

\section{Abbreviations}

DEX, dexamethasone

AOE, antioxidant enzyme

SOD, superoxide dismutase

CAT, catalase

GP, glutathione peroxidase

DSPC, disaturated phosphatidylcholine

BPD, bronchopulmonary dysplasia

Synthetic glucocorticoids have been used extensively in situations of premature labor with threatened delivery of a very

Received October 31, 1991; accepted April 3, 1992.

Correspondence: Lee Frank, M.D., Ph.D., Pulmonary Research Center (R-120), University of Miami School of Medicine, P.O. Box 016960, Miami, FL 33101.

Supported in part by Departments of Medicine and Pediatrics/Pulmonary Research Center, University of Miami School of Medicine and NIH Research Grant No. HL-26029. immature infant. Administration of a long-acting glucocorticoid for $48 \mathrm{~h}$ before premature delivery may successfully stimulate surfactant production/secretion in the immature fetal lung and lessen the chance of serious respiratory distress syndrome in the prematurely delivered newborn (1).

Previous work from our laboratories has demonstrated that the prenatal administration of DEX to pregnant rats will not only accelerate the late gestational development of the surfactant system in the rat fetuses, but will also accelerate the normal late gestational development of the fetal lung AOE system (2). The late gestational rise in fetal lung SOD, CAT, and GP activities, now demonstrated to be a natural maturational occurrence in five animal species (rat, mouse, rabbit, hamster, and sheep) (38 ), is proposed to be the biochemical means by which the lung is prepared for its safe transition from the quite hypoxic in utero environment to the relatively $\mathrm{O}_{2}$-rich ex utero environment it will encounter immediately at birth $(3-5,9)$.

Because of its marked stimulatory effect on fetal lung AOE system development, we wondered if prenatal DEX treatment might also have a salutary effect on the ability of the newborn animal to tolerate early and prolonged exposure to hyperoxia. We describe herein the findings from a series of hyperoxic exposure experiments that consistently demonstrated an improved resistance to pulmonary $\mathrm{O}_{2}$ toxicity in the newborn offspring from prenatally DEX-treated dams compared to control newborn rat pups.

\section{MATERIALS AND METHODS}

Animals/treatments. We used adult female Sprague-Dawley albino rats $(300 \mathrm{~g})$ (originally obtained from Charles River Laboratories, Wilmington, MA), which were in our rat breeding program colonies in the University of Miami Animal Care Facility. Breeding was accomplished by allowing female and male rats to cohabit overnight. Probable pregnancy was determined by a positive sperm smear the next morning, and the onset of gestation was considered to be the midpoint of the 12-h cohabitation period. The length of gestation averages $21.5 \mathrm{~d}$ in these animals, with only slight variations (SD $= \pm 0.23 \mathrm{~d}$ ) noted in several hundred monitored pregnancies.

At 48 and $24 \mathrm{~h}$ before the expected time of delivery, pregnant animals (two or four per experiment) were given intraperitoneal injections of DEX, $0.4 \mathrm{mg} / \mathrm{kg} / \mathrm{d}$ (dexamethasone sodium phosphate; Henry Schein, Inc., Woodbury, NY) diluted in physiologic saline, or were handled in the exact manner and given intraperitoneal injections of physiologic saline (two or four per experiment). Shortly after delivery, all the newborn pups were removed from the mothers, marked by toe-clipping (DEX or saline pretreated), and pooled together before being randomly redistributed to the newly delivered mother rats, one half of which were then placed in the $\mathrm{O}_{2}$ exposure chambers and one half of which remained in room air. Litter sizes were 10 to 12 pups per dam.

Exposures to hyperoxia were conducted in clear plastic $3.5-\mathrm{ft}^{3}$ 
exposure chambers with continuous monitoring of $\mathrm{O}_{2}$ concentration ( 96 to $98 \% \mathrm{O}_{2}$; oxygen analyzer, model OM-11; Beckman Instruments, Inc., Fullerton, $\mathrm{CA}), \mathrm{CO}_{2}$ concentration $(<0.5 \%$, Beckman medical gas analyzer, model LB-2), temperature (23$25^{\circ} \mathrm{C}$, in-chamber thermometers), and humidity (50 to $70 \%$, inchamber hygrometers). Exposures to $>95 \% \mathrm{O}_{2}$ were continuous for 7 to $14 \mathrm{~d}$ except for a daily 15 - to 20 -min period when the chambers were opened for animal maintenance purposes and for switching the dams from $\mathrm{O}_{2}$ litters to air litters to prevent the development of $\mathrm{O}_{2}$ toxicity in the nurturing dams. Daily litter weights were also obtained to check for possible poor nursing by specific dams, but no replacement dams were ever required. The experimental animal protocol for these studies was preapproved by the University's Animal Research Use Committee.

Biochemical analyses. For lung AOE analysis, some of the experimental pups were killed by an intraperitoneal overdose of pentobarbital after variable periods in hyperoxia or room air. After the great vessels in the abdomen were severed to exsanguinate the animals, their lungs were rapidly perfused in situ with ice-cold isotonic buffer $(0.1 \mathrm{M}$ potassium phosphate, 0.15 $\mathrm{M}$ potassium chloride, $\mathrm{pH} 7.4$ ) via the pulmonary artery after removing the left atrial appendage for ease of drainage. The dissected lungs were then homogenized in ice-cold $0.005 \mathrm{M}$ potassium phosphate buffer, $\mathrm{pH} 7.8(1: 20 \mathrm{wt} / \mathrm{vol})$ with a Brinkmann Polytron homogenizer (Brinkmann Instruments, Co., Westbury, NY). SOD activity was measured on fresh homogenates using the spectrophotometric ferricytochrome reduction method (10). The crude lung homogenate was centrifuged at $15000 \times g$ for $10 \mathrm{~min}$ at $5^{\circ} \mathrm{C}$ and the supernatant fluid was removed and frozen overnight. CAT activity (11) and GP activity (12) in the supernatant fluid were measured spectrophotometrically the next day. The CAT assay monitors the rate of loss of $\mathrm{H}_{2} \mathrm{O}_{2}$ substrate at $240 \mathrm{~nm}$; the GP assay follows the rate of NADPH oxidation in the presence of cumene hydroperoxide substrate at $340 \mathrm{~nm}$. Purified enzyme standards were obtained from Sigma Chemical Co., St. Louis, MO (SOD and CAT) and Boehringer Mannheim Co., Indianapolis, IN (GP). Lung protein was determined with purified bovine albumin (Sigma) as standard (13), and lung DNA was determined with calf thymus DNA (Sigma) as standard (14). Lung enzyme activity was calculated on the basis of activity per $\mathrm{g}$ lung, per $\mathrm{mg}$ protein, and per $\mathrm{mg}$ DNA, with the latter values used for statistical comparisons because this expression of sp act best reflects the enzyme activity per lung cell, which is what is most meaningful in lung cell protective capacity versus oxidant stress.

For DSPC determinations, aliquots of the homogenates were subjected to lipid extraction using the method of Bligh and Dyer (15). The extract was dried under nitrogen, reconstituted with chloroform:methanol $(2: 1)$, and assayed for total lipid phosphorus following the method of Morrison (16). A portion of the dried lipid extract was used to isolate DSPC using the osmium tetroxide method described by Mason et al. (17) and then assayed for inorganic phosphorus as described above (16). A known quantity of $\left[{ }^{14} \mathrm{C}\right]$-dipalmitoylphosphatidylcholine (New England Nuclear, North Billerica, MA) was added before lipid extraction to estimate and correct for sequential losses. DSPC was expressed as $\mathrm{mg} / \mathrm{g}$ of wet lung weight.

Lung lipid peroxidation was assayed by conjugated diene measurements in air- and $\mathrm{O}_{2}$-exposed rat lungs (18). This assay involves homogenizing the perfused lungs in isotonic phosphate buffer containing $0.001 \mathrm{M}$ EDTA. After centrifugation, the homogenate is extracted with 2 volumes of $45^{\circ} \mathrm{C}$ methanol:chloroform $(1: 2)$ two times, then once with $\mathrm{H}_{2} \mathrm{O}$ :methanol: chloroform (1:1:2) After centrifugation, the methanol- $\mathrm{H}_{2} \mathrm{O}$ upper phase is aspirated off and a $2-\mathrm{mL}$ aliquot of the chloroform extract is dried in a water bath at $40-50^{\circ} \mathrm{C}$ under $\mathrm{N}_{2}$. The lipid residual is redissolved in $3 \mathrm{~mL}$ of heptane and the absorption spectrum at $223 \mathrm{~nm}$ is recorded against a heptane blank. Results are expressed as absorbance units per $\mathrm{g}$ wet lung and per mg DNA.
Lung elastin was assayed by the spectrophotometric method of Naum and Morgan (19). After homogenizing the lungs in 0.15 $\mathrm{M} \mathrm{NaCl}$ and centrifugation, $1.0 \mathrm{~mL}$ of $5 \mathrm{M}$ guanidine $\mathrm{HCl}, \mathrm{pH}$ 7.0 , is added to the pellet. Guanidine extraction continues for 24 $\mathrm{h}$ at room temperature in a shaking water bath. After centrifugation and a second 24-h extraction with guanidine, the residue is suspended in $1.0 \mathrm{~mL} \mathrm{H}_{2} \mathrm{O}$ and then autoclaved at $15 \mathrm{lb}$ pressure for $45 \mathrm{~min}$. After centrifugation, the precipitate is mixed with $1.0 \mathrm{~mL} \mathrm{H}_{2} \mathrm{O}$ and $1.0 \mathrm{~mL}$ elastase solution $(0.1 \mathrm{mg}$ purified elastase in $0.1 \mathrm{M}$ veronal acetate buffer, $\mathrm{pH} 8.8$ ) and incubated for $30 \mathrm{~min}$ at $37^{\circ} \mathrm{C}$ in a shaking water bath. Aliquots are then assayed for protein (elastin) content (13). Purified standards of elastin (Sigma) are treated as above for generation of a standard assay curve.

Lung morphometry. For microscopic studies, animals were killed as above and then had their lungs fixed in situ via a tracheal cannula using a constant inflation pressure of $20 \mathrm{~cm}$ $\mathrm{H}_{2} \mathrm{O}$ (fixative $=10 \%$ buffered formalin, $\mathrm{pH} 7.4$ ). After fixation in the inflated state for $24-48 \mathrm{~h}$, the tissue is processed for hematoxylin and eosin staining. Similarly oriented sections of left lung and right middle and lower lobe are used.

Light level morphometric assessment was done on coded slides for comparison of lung structural development (alveolarization) in air- and $\mathrm{O}_{2}$-exposed neonatal animals of both experimental groups. We determined mean linear intercept, \% air/\% tissue space, internal surface area (ISA), and specific internal surface area (ISA/100 g body wt) as we have reported previously (20), using $\times 450$ magnification and an eyepiece with a simple square grid pattern (square grid with seven horizontal lines and 42 intercept bars, model CPLW 10X/18 eyepiece; Zeiss Optical, Hanover, MD). A minimum of 30 lung fields per animal were examined. To calculate the mean linear intercept $\left(\mathrm{L}_{\mathrm{M}}\right)$ (representing the average distance between air space walls, or average airspace diameter), we used the formula $\mathrm{L}_{M}=\mathrm{n} \cdot \mathrm{L} / \mathrm{\epsilon}$, where $\mathrm{n}$ is the number of lines counted, $\mathrm{L}$ is the length of the line, and $\epsilon \mathrm{i}$ is the sum of septal (walls of air spaces) intercepts. To calculate the ISA, we use the formula ISA $=4 \cdot \mathrm{VL} / \mathrm{L}_{\mathrm{M}}$, where $\mathrm{VL}$ is the postfixation lung volume by water displacement $(21,22)$.

Pathologic assessment was done on additional coded lung sections, looking for evidence of interstitial, periarterial/peribronchiolar edema and intraalveolar edema in the $\mathrm{O}_{2}$-exposed rat lungs. Pulmonary edema was also assessed by lung wet weight/dry weight ratios $\left[80^{\circ} \mathrm{C}\right.$ oven; lungs dried until constant weight found (48 h)].

Statistical analyses. For quantitative comparisons of the DEX versus control groups, $t$ testing was done. For four group comparisons (control air $+\mathrm{O}_{2}$, DEX air $+\mathrm{O}_{2}$ ), one-way analysis of variance testing was done, followed by Duncan's multiple-range testing, using a $p<0.05$ value for statistical significance. Survival data were compared for significance using $\chi^{2}$ testing (23).

\section{RESULTS}

Prenatal treatment effects on newborn offspring. Tables 1 and 2 provide comparative gravimetric, biochemical, and lung morphometric data on the newborn offspring of the DEX-and salinetreated dams. Prenatal DEX treatment resulted in significantly reduced body weight and lung weight in the newborn pups as noted before by us and many other investigators (2, 24-26). However, the lung weight/body weight ratio was no different than for the control (saline) newborns. Prenatal DEX treatment also resulted in significant reductions in lung protein and DNA content compared to the control group of newborns, but when calculated as $\mathrm{mg} / \mathrm{g}$ lung weight, the group values were not significantly different.

In this study, as was found in our earlier study (2), newborn pups of both treatment groups had essentially similar lung surfactant (DSPC) contents as well as AOE activities (SOD, CAT, and GP) at birth (Fig. 1). Although prenatal DEX treatment elevates the levels of surfactant and AOE in the premature animal 
Table 1. Comparative parameters in newborn rat pups after prenatal DEX or saline treatment*

\begin{tabular}{|c|c|c|c|c|c|c|}
\hline Treatment group & Body wt (g) & $\begin{array}{l}\text { Left lung wt } \\
(\mathrm{g})\end{array}$ & Lung wt/body wt & $\begin{array}{c}\text { Protein } \\
\text { (mg/lung) }\end{array}$ & $\begin{array}{c}\text { DNA } \\
\text { (mg/lung) }\end{array}$ & Protein/DNA \\
\hline Saline $(n=10)$ & $5.96 \pm 0.41$ & $0.054 \pm 0.006$ & $0.906 \pm 0.072$ & $2.39 \pm 0.12$ & $0.83 \pm 0.09$ & $2.89 \pm 0.12$ \\
\hline $\operatorname{DEX}(n=12)$ & $\begin{array}{c}4.93 \pm 0.41 \\
(\downarrow 17 \%)\end{array}$ & $\begin{array}{c}0.040 \pm 0.003 \dagger \\
(\downarrow 26 \%)\end{array}$ & $\begin{array}{c}0.828 \pm 0.112 \\
(\downarrow 9 \%)\end{array}$ & $\begin{array}{c}1.87 \pm 0.31 \dagger \\
(\downarrow 22 \%)\end{array}$ & $\begin{array}{l}0.67 \pm 0.11 \dagger \\
(\downarrow 19 \%)\end{array}$ & $\begin{array}{c}2.80 \pm 0.29 \\
(\downarrow 3 \%)\end{array}$ \\
\hline
\end{tabular}

* Newborn offspring from pregnant rats treated at 48 and $24 \mathrm{~h}$ before delivery with DEX $0.4 \mathrm{mg} / \mathrm{kg}$ or equivolume saline and killed at the time of birth. Values are mean \pm 1 SD for $n$ rat pups/group.

$\dagger p<0.05$ for DEX vs saline values.

Table 2. Comparative morphometry of newborn rat lungs after prenatal DEX or saline treatment*

\begin{tabular}{ccccccc}
\hline Treatment group & Body wt $(\mathrm{g})$ & $\mathrm{LV}(\mathrm{mL})$ & $\mathrm{LV} / 100 \mathrm{~g}$ & $\mathrm{~L}_{\mathrm{M}}(\mu \mathrm{m})$ & ISA $\left(\mathrm{cm}^{2}\right)$ & ISA $/ 100 \mathrm{~g}$ \\
\hline Saline $(n=8)$ & $6.15 \pm 0.60$ & $0.30 \pm 0.03$ & $4.83 \pm 0.25$ & $55.4 \pm 2.2$ & $210 \pm 30$ & $3489 \pm 135$ \\
DEX $(n=6)$ & $4.75 \pm 0.35 \dagger$ & $0.22 \pm 0.02 \dagger$ & $4.73 \pm 0.19$ & $57.7 \pm 2.2$ & $154 \pm 16 \dagger$ & $3284 \pm 153$ \\
& $(\downarrow 23 \%)$ & $(\downarrow 27 \%)$ & $(\downarrow 2 \%)$ & $(\uparrow 4 \%)$ & $(\downarrow 27 \%)$ & $(\downarrow 5 \%)$ \\
\hline
\end{tabular}

* Newborn offspring from pregnant rats treated at 48 and $24 \mathrm{~h}$ before delivery with DEX $0.4 \mathrm{mg} / \mathrm{kg}$ or equivolume saline and killed at the time of birth. Values are means \pm 1 SD for $n$ lungs per group. LV, lung volume; $\mathrm{L}_{\mathrm{M}}$, mean linear intercept (average airspace diameter); and ISA, internal surface area.

$\dagger p<0.05$ for DEX vs saline values.
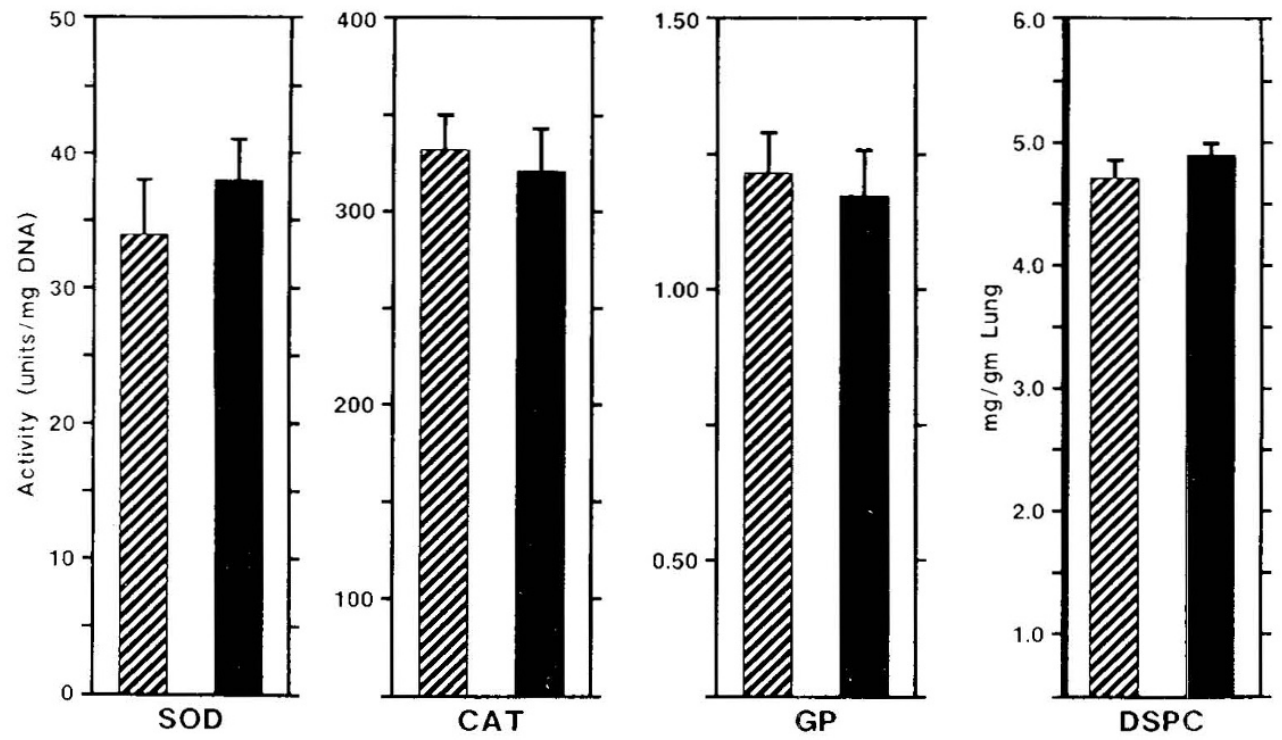

Fig. 1. Pulmonary AOE and lung surfactant (DSPC) content in newborn rat pups prenatally treated with DEX (black bars) or saline (hatched bars) and killed at the time of birth. No differences between groups are seen. Values = mean \pm 1 SD for 12 pups per group.

lung, greater than normal full-term lung levels are not found at the time of birth.

Lung morphometric analysis of newborn lung structure (Table 2) showed DEX treatment effects on absolute lung volume and lung internal surface area. However, when normalized to body weight, these values were similar for both experimental groups, as were the mean airspace diameters $\left(\mathrm{L}_{\mathrm{M}}\right)$. Lung elastin contents were similarly unchanged in the DEX $(0.177 \pm 0.015 \mathrm{mg} / \mathrm{lung})$ versus the control pups $(0.190 \pm 0.003 \mathrm{mg} / \mathrm{lung}, n=5$ per group, $p>0.10)$.

Survival in hyperoxia. In each of nine separate hyperoxia exposure experiments, the prenatal DEX-treated pups demonstrated a greater percentage of survival than the simultaneously exposed control pups in $\mathrm{O}_{2}$. Figure 2 illustrates the composite survival percentages.

The DEX-treated pups had significantly improved $\mathrm{O}_{2}$ tolerance between exposure $\mathrm{d} 7$ and 14 inclusive $(p<0.01$ or greater by $\chi^{2}$ testing).

In addition to survival per se, the DEX group had other indications of superior $\mathrm{O}_{2}$ tolerance by comparative lung wet weight/dry weight ratios (reflection of pulmonary edema), comparative conjugated diene levels (as an index of $\mathrm{O}_{2}$ radicalinduced lipid peroxidation), and comparative light microscopic

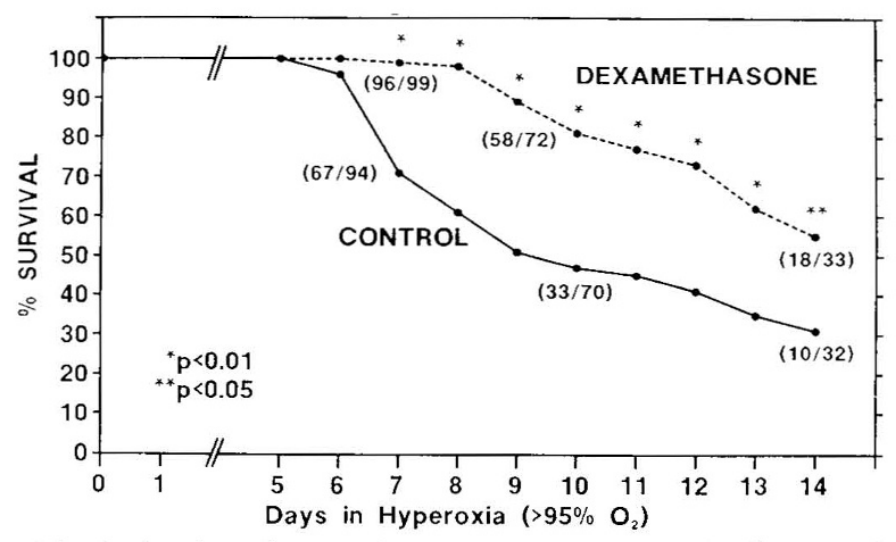

Fig. 2. Survival of prenatal DEX-treated and prenatal saline-treated (control) newborn pups in $>95 \% \mathrm{O}_{2}$ for $14 \mathrm{~d}$ (numbers in parentheses = number alive/number put in $\mathrm{O}_{2}$ ). $\mathrm{O}_{2}$-DEX pup survival rate is significantly improved compared to $\mathrm{O}_{2}$ controls at all time periods from 7 to $14 \mathrm{~d}$ in hyperoxia $\left({ }^{*}, p<0.01 ;{ }^{* *}, p<0.05 ; \chi^{2}\right)$. 

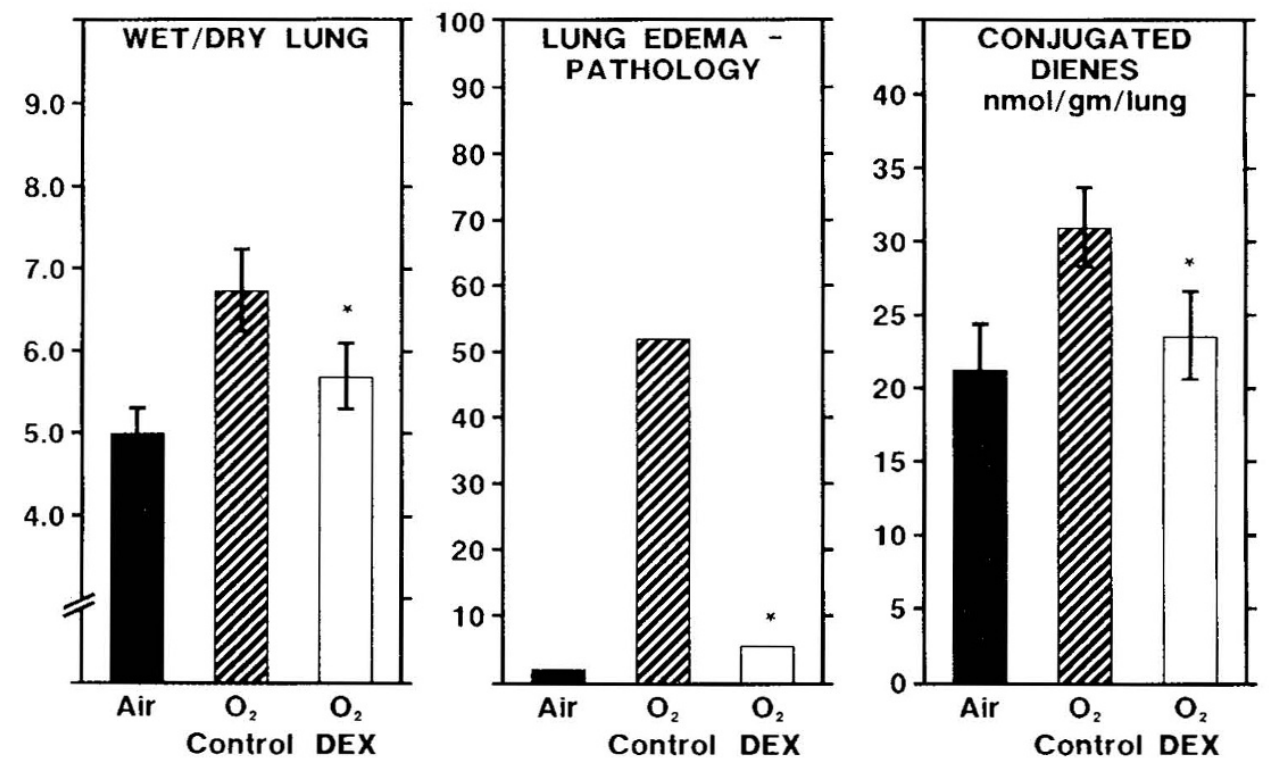

Fig. 3. Comparative evidence for pulmonary $\mathrm{O}_{2}$ toxicity in prenatal DEX-treated and saline-treated (control) newborn rats after $7 \mathrm{~d}$ in $>95 \%$ $\mathrm{O}_{2}$. DEX-treated group values in air were similar for all parameters to the control (saline) air group values $(n=6)$, which are illustrated here. Lung wet weight/dry weight values $=$ mean $\pm 1 \mathrm{SD}$ for 10 pups per $\mathrm{O}_{2}$ group. Lung edema by microscopic pathology $(\%)=$ number with intraalveolar edema fluid per total number of lung sections examined (= 73 per group). Conjugated dienes, values $=$ mean \pm 1 SD for six samples per group. $*$, $p<0.05$ for $\mathrm{O}_{2}$-DEX vs $\mathrm{O}_{2}$-saline group.

pathologic findings (Fig. 3). The lung wet weight/dry weight ratio averaged $35 \%$ higher than the air control value in the $\mathrm{O}_{2}$-saline pups versus $15 \%$ higher than the air control values in the $\mathrm{O}_{2}$ DEX pups $(p<0.05)$. Conjugated dienes in the lung were increased $46 \%$ in the $\mathrm{O}_{2}$-saline group versus $11 \%$ in the $\mathrm{O}_{2}$-DEX pups $(p<0.05)$. On light microscopic examination, all the $\mathrm{O}_{2^{-}}$ exposed pups had perivascular/peribronchiolar edema present after $7 \mathrm{~d}$ in $\mathrm{O}_{2}$. However, as evidence of more advanced $\mathrm{O}_{2}$ toxicity, intraalveolar edema was present in four of $73(5.5 \%)$ $\mathrm{O}_{2}$-DEX lung sections compared to 38 of $73(52 \%) \mathrm{O}_{2}$ control group lung sections $(p<0.001)$ (Fig. 3 ).

Lung responses to hyperoxia. The responses of the surfactant system to $7 \mathrm{~d}$ in $\mathrm{O}_{2}$ were very similar in the two treatment groups, with the $\mathrm{O}_{2}$ control group showing a $37 \pm 4 \%$ increase in lung tissue DSPC content in response to hyperoxia versus a $39 \pm 8 \%$ increase in the DEX-O $\mathrm{O}_{2}$ pup lungs (both values $p<0.05$ versus respective air controls). Figure 4 illustrates the comparative responses of the pulmonary $\mathrm{AOE}$ to hyperoxic exposure in the two groups of offspring at 2,4 , and $7 \mathrm{~d}$ of $>95 \% \mathrm{O}_{2}$ exposure. After $2 \mathrm{~d}$ in hyperoxia, a trend toward a greater AOE response was seen in the DEX group, with SOD, CAT, and GP enzymes already significantly elevated in $\mathrm{O}_{2}$ versus the air control group values at this early time point. Only CAT activity showed elevation at the 2-d time point in the $\mathrm{O}_{2}$ control group. Although both newborn groups manifested significant increases in SOD, CAT, and GP activities (compared to air control values) at 4 and $7 \mathrm{~d}$ of high $\mathrm{O}_{2}$ exposure, at both time points the comparative increases in AOE were significantly enhanced in the $\mathrm{O}_{2}$-DEX group versus the changes in the $\mathrm{O}_{2}$ control group levels in response to hyperoxia $(p<0.05)$.

The lung morphometric changes induced by prolonged $>95 \%$ $\mathrm{O}_{2}$ exposure in both groups of neonates are shown in Table 3. The improved survival of the DEX offspring in hyperoxia was not accompanied by any differences in the degree of $\mathrm{O}_{2}$-induced inhibition of normal lung structural maturation (alveolarization and increase in respiratory surface area) that occurred during hyperoxia. Compared to the air control values, the lungs of both $\mathrm{O}_{2}$-exposed groups had significantly enlarged mean airspace diameters and significantly reduced respiratory exchange surface area and surface area $/ 100 \mathrm{~g}$ body wt. Figure 5 shows comparative lung micrographs illustrating the marked inhibition of alveolarization in the lungs of both $\mathrm{O}_{2}$-exposed groups of pups. Addi- tionally, the typical presence of alveolar edema in the $\mathrm{O}_{2}$ control group versus the prenatal DEX-O $\mathrm{O}_{2}$ group is demonstrated in these light-level micrographs.

\section{DISCUSSION}

The effects of prenatal glucocorticoid treatment on the maturation of the fetal lung continues to be extensively explored both in vivo and in vitro. Most experimental work continues to focus on the important effect of prenatal glucocorticoids on accelerating the maturation of the surfactant system (and its associated biosynthetic enzymes). Newer work has centered on the effects of glucocorticoids on development changes in the surfactantrelated proteins, SP-A, SP-B, and SP-C (26). This very extensive research effort complements the widespread use of prenatal glucocorticoid treatment in threatened human premature labor to try to stimulate early surfactant production and secretion by the premature fetus and prevent serious respiratory distress syndrome if premature delivery eventuates.

Newborn infants who are born too soon, especially those < $1000 \mathrm{~g}$ (very low birth weight), are excessively prone to developing early and severe lung damage secondary to barotrauma and required high $\mathrm{O}_{2}$ therapy, which all too often may progress to chronic lung disease or BPD. The more premature the infant, the more distressingly high becomes the clinical incidence of BPD (27). Protection of the lung from the injurious effects of high $\mathrm{O}_{2}$ exposure depends on a variety of known and still unknown factors. The pulmonary AOE have been consistently shown to be the primary defensive system against the increased $\mathrm{O}_{2}$ free radicals that are produced in cells under hyperoxic conditions $(4,28,29)$.

In the last couple of years, some interesting information has been garnered that indicates that in parallel to the developmental profile of the fetal lung surfactant system in late gestation the AOE system of the fetal lung also demonstrates marked increases in activity during the final in utero period before birth. This late gestational increase in fetal lung AOE activities has been found to occur in all species examined, including the rat, hamster, guinea pig, rabbit, and sheep (3-8). A single report from a small sampling of human infants suggests that late gestational AOE changes in the human fetal lung may also be a normal phenomenon (30). The similar chronology of development of the fetal 


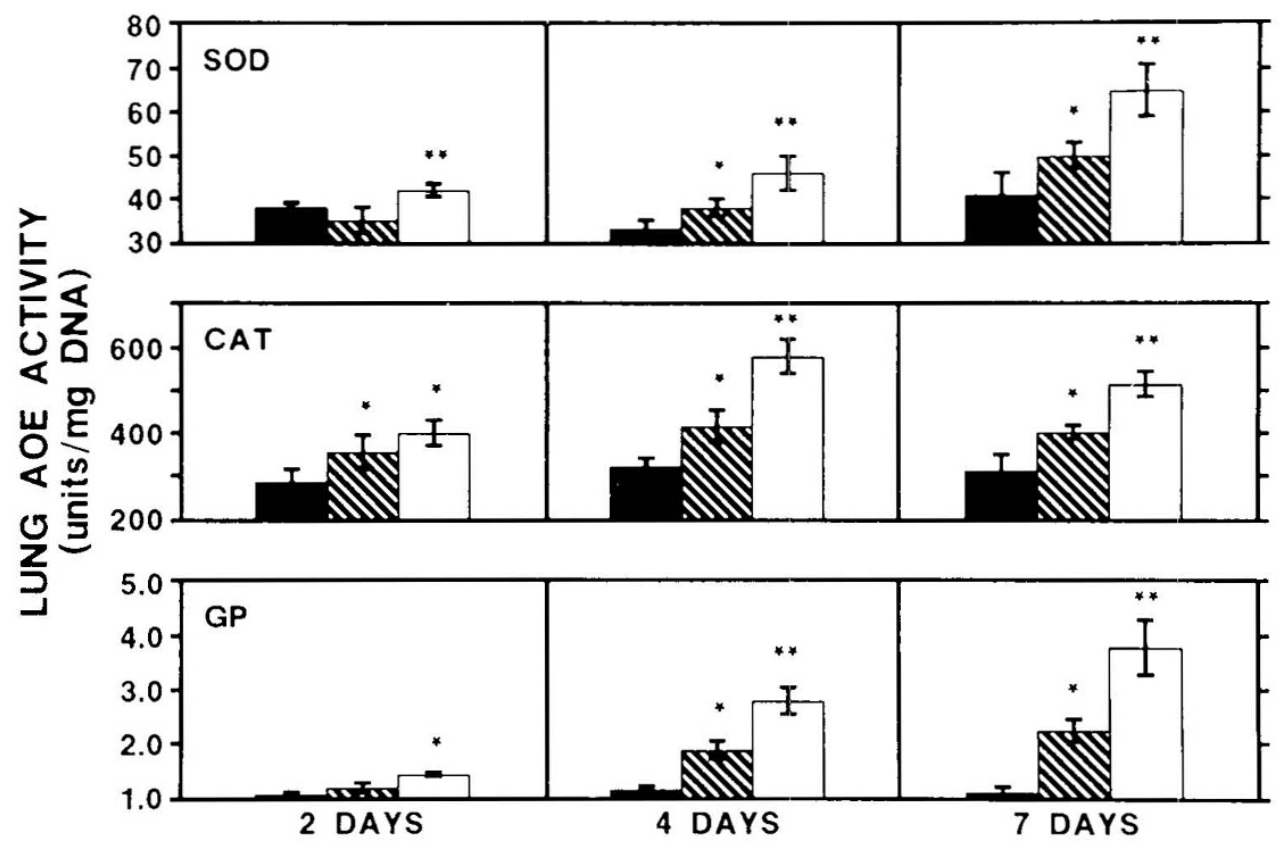

Fig. 4. Comparative AOE responses to hyperoxia in prenatal DEX-treated (white bars) and prenatal saline-treated (hatched bars) newborn rats at 2, 4, and $7 \mathrm{~d}$ of $>95 \% \mathrm{O}_{2}$ exposure. Lung AOE values in the air-exposed prenatal DEX-treated group were equivalent to the air-exposed control (saline) group values, which are illustrated here (black bars). AOE values $=$ mean \pm 1 SD for four air control and six to eight $\mathrm{O}_{2}$ lung samples per group at each time period. Note that ordinate values do not start at zero activity. ${ }^{*}, p<0.05$ for $\mathrm{O}_{2}$ group $v s$ air group. ${ }^{* *}, p<0.05$ for $\mathrm{O}_{2}$-DEX $v s$ $\mathrm{O}_{2}$-saline and air group.

Table 3. Comparative morphometry of newborn rat pups after $10 \mathrm{~d}$ in $>95 \% \mathrm{O}_{2}$ or room air*

\begin{tabular}{lllllll}
\hline Treatment group & Body wt $(\mathrm{g})$ & $\mathrm{LV}(\mathrm{mL})$ & $\mathrm{LV} / 100 \mathrm{~g}$ & $\mathrm{~L}_{\mathrm{M}}(\mu \mathrm{m})$ & $\mathrm{ISA}\left(\mathrm{cm}^{2}\right)$ & ISA $/ 100 \mathrm{~g}$ \\
\hline Air control $(n=6)$ & $19.8 \pm 1.0$ & $0.99 \pm 0.06$ & $5.01 \pm 0.21$ & $46.6 \pm 1.4$ & $850 \pm 56$ & $4303 \pm 238$ \\
$\mathrm{O}_{2}$-saline $(n=5)$ & $17.2 \pm 1.8 \dagger$ & $0.76 \pm 0.07 \dagger$ & $4.50 \pm 0.19$ & $68.4 \pm 5.1 \dagger$ & $458 \pm 18 \dagger$ & $2726 \pm 248 \dagger$ \\
$\mathrm{O}_{2}$-DEX $(n=9)$ & $17.3 \pm 1.9 \dagger$ & $0.79 \pm 0.08 \dagger$ & $4.61 \pm 0.57$ & $66.5 \pm 3.8 \dagger$ & $476 \pm 48 \dagger$ & $2769 \pm 416 \dagger$ \\
\hline
\end{tabular}

* Ten-d-old rat pups from pregnant rats prenatally treated at 48 and $24 \mathrm{~h}$ before delivery with DEX or equivolume saline. Values are mean \pm 1 $\mathrm{SD}$ for $n$ rat lungs per group. Air DEX group values were statistically similar to the air control (saline) values shown. LV, lung volume; $\mathrm{L}_{\mathrm{M}}$, mean linear intercept (average airspace diameter); and ISA, lung internal surface area.

$\dagger p<0.05$ for $\mathrm{O}_{2}$-exposed group $v s$ air-controls.

lung surfactant and AOE systems suggested that perhaps both systems share common regulatory mechanisms. And, when pregnant rats were administered DEX at 48 and $24 \mathrm{~h}$ before delivery, it was found that rat fetuses delivered prematurely at 20 and 21 d gestation (term $=22 \mathrm{~d}$ ) demonstrated significantly elevated lung levels of DSPC (expected), as well as significantly elevated SOD, CAT, and GP activities (hypothesized) compared to salinetreated control fetuses (2).

Because of this stimulatory effect of prenatal DEX treatment on the protective AOE system of the immature lung, we questioned whether prenatal DEX treatment might result in some more prolonged beneficial effects on the ability of the newborn animal to tolerate prolonged hyperoxia. And, as we report herein, the hyperoxic tolerance effect of prenatal DEX treatment resulted in superior survival of the prenatal DEX-exposed pups in $>95 \%$ $\mathrm{O}_{2}$ in nine of nine experiments compared to control newborn rats and significantly increased the composite percentage of survival from d 7 through 14 of $\mathrm{O}_{2}$ exposure (Fig. 2). Similarly, signs of classic $\mathrm{O}_{2}$ toxicity including lung edema and associated lipid peroxidation were significantly reduced in the prenatal DEX $\mathrm{O}_{2}$ group compared to the control newborns in hyperoxia (Fig. 3).

To try to explain the basis for the improved $\mathrm{O}_{2}$ tolerance of the prenatally treated DEX pups, we examined a variety of comparative parameters both at the time of birth and during hyperoxic exposure. The data in Tables 1 and 2 and Figure 1 fail to provide any explanation for the improved $\mathrm{O}_{2}$ tolerance of the prenatal DEX newborns. There was no evidence at the time of beginning high $\mathrm{O}_{2}$ exposure for any group differences in lung structural maturation (alveolarization), lung tissue DSPC content, or pulmonary AOE activities.

During exposure to $>95 \% \mathrm{O}_{2}$, we found similar increases in lung DSPC content in both groups of neonates. Similarly, the quantitative morphometric data, after $10 \mathrm{~d}$ in $\mathrm{O}_{2}$, showed very similar $\mathrm{O}_{2}$-induced lung alterations in the two experimental groups. The inhibition of normal lung development (alveolarization) in hyperoxia is considered a growth-specific effect of high $\mathrm{O}_{2}$ rather than a classic pathologic finding. It's believed to be related to the inhibitory effect of $\mathrm{O}_{2}$ on DNA, protein, and elastin synthesis and may occur in early postnatal lungs that are relatively free of severe $\mathrm{O}_{2}$ toxicity pathology (31).

The key difference that was found between the prenatal DEX and the saline pups in $\mathrm{O}_{2}$ was in the pulmonary AOE responses induced by hyperoxic exposure (Fig. 4). Although both experimental groups of newborns were able to mount an AOE response to $\mathrm{O}_{2}$ challenge, the prenatal DEX pups demonstrated an earlier, more consistently enhanced AOE response to hyperoxia than the $\mathrm{O}_{2}$ saline pups at each time interval tested. Thus, based on the various parameters that we examined, a possible explanation for the significantly improved $\mathrm{O}_{2}$ tolerance of the prenatally DEXtreated newborns is the accelerated and increased $\mathrm{AOE}$ responsiveness of their lungs to $>95 \% \mathrm{O}_{2}$ exposure. Hyperoxia disrupts the normal oxidant-antioxidant balance in (lung) cells because of markedly increased rates of $\mathrm{O}_{2}$ free radical production (32, 33 ). The more rapidly and more completely this oxidant-antioxidant imbalance can be restored to normal by increasing the 


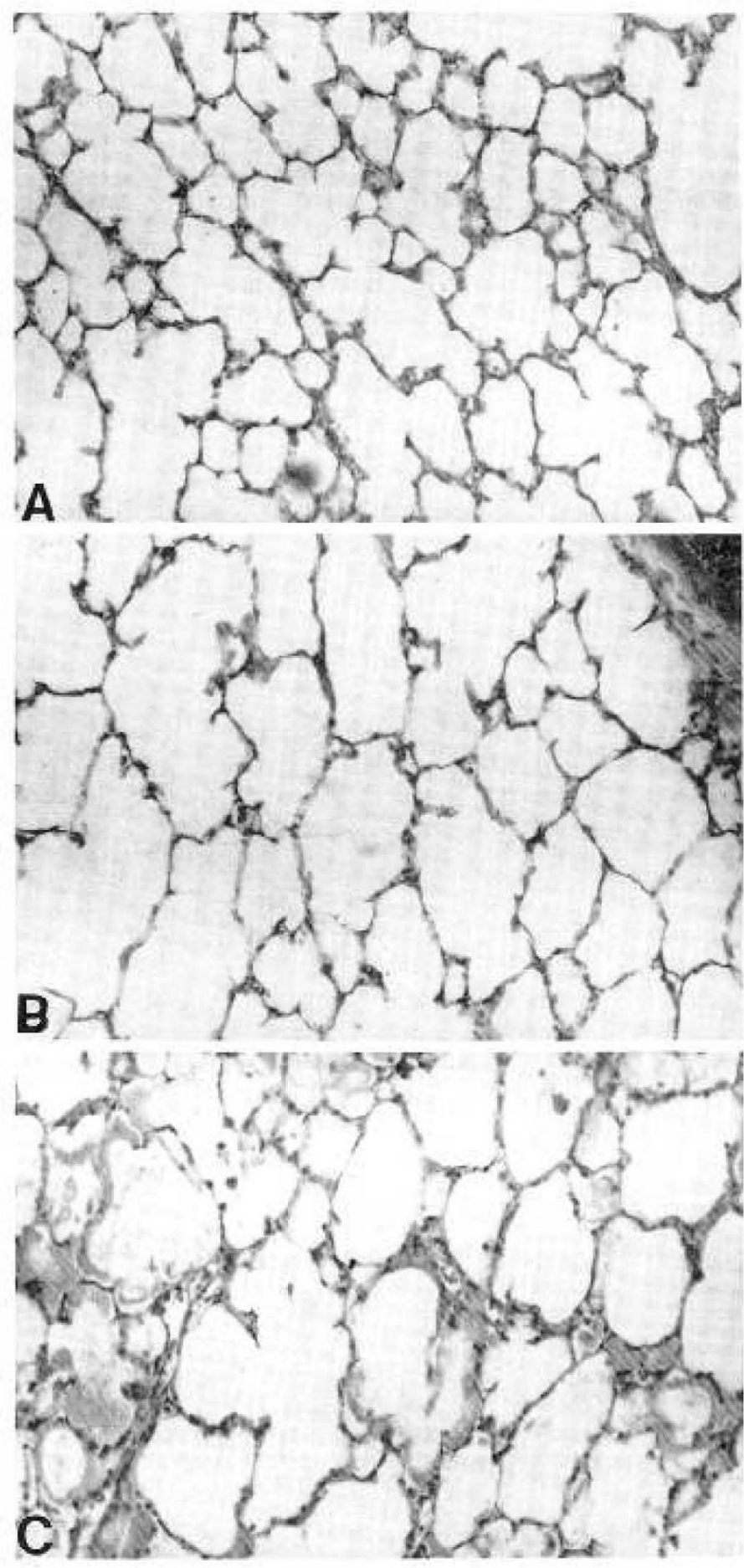

Fig. 5. Light micrographs of lungs of air controls $(A), \mathrm{O}_{2}$-prenatal DEX-treated rats $(B)$, and $\mathrm{O}_{2}$ control rats $(C)$. Both groups of $\mathrm{O}_{2}$-exposed rat pups demonstrate $\mathrm{O}_{2}$-induced inhibition of normal lung structural development (alveolarization) compared to air controls. The lungs of the pups maintained in air $(A)$ have many small alveolar airspaces apparent compared to the larger, more saccular airspaces of the $\mathrm{O}_{2}$-exposed rat pups $\left(>95 \% \mathrm{O}_{2} ; 10 \mathrm{~d}\right)$. In addition, lung of the $\mathrm{O}_{2}$ control group $(C)$ shows evidence of intraalveolar edema, which is absent from lung of $\mathrm{O}_{2-}$ prenatal DEX group lungs $(B)$. Original magnification $\times 450$; hematoxylin and eosin stain.

endogenous antioxidant defenses, the more effectively $\mathrm{O}_{2}$-induced lung injury can be ameliorated. However, even animals with elevated pulmonary $\mathrm{AOE}$ may die of progressive lung damage after more prolonged periods in hyperoxia. This is true of newborn rats (including the prenatal DEX treatment group) as well as adult rats treated with exogenous $\mathrm{AOE}$ (liposomal $\mathrm{SOD}, \mathrm{CAT}$ ) to extend their survival time in $>95 \% \mathrm{O}_{2}$. Presumably, the elevated AOE may still be insufficient to detoxify the increased quantity of $\mathrm{O}_{2}$ radicals generated in $>95 \% \mathrm{O}_{2}$, and/or specific vital intracellular sites of $\mathrm{O}_{2}$ radical generation or injury (e.g. nuclear DNA) may be inaccessible to the protection offered by increased cytosolic or mitochondrial AOE activity $(31,34$, 35).

Because of the protean nature of glucocorticoid actions, there may be other explanations for why prenatal DEX treatment can protect against the pathologic lung changes associated with hyperoxia (Fig. 3) and improve the survival of newborn rats in hyperoxia. Also, although prenatal DEX treatment results in a persistently more pronounced newborn animal AOE response to hyperoxic challenge, how this response in the postnatal period is mediated by exposure to DEX in the prenatal period is an unanswered question. An interesting study by Schellenberg et al. (36), who investigated the ontogeny of elastin and collagen development in the late fetal to 30 -d-old rat lung, essentially raised this same question. When these investigators tested the effect of prenatal DEX treatment on the normal course of postnatal mesenchymal tissue development, they found that their prenatally DEX-exposed pups showed normal lung elastin contents at birth and at age $5 \mathrm{~d}$, but significant decreases in lung elastin content spanning the period of postnatal d 10 to 20 . Because, as in our newborns in $\mathrm{O}_{2}$, this could not possibly be related to exogenous DEX still in the circulation $\left(t_{1 / 2}=5 \mathrm{~h}\right.$ in the rat), these authors referred in their discussion to the earlier ideas of Davies and Reid (37) that prenatal hormonal treatment can interfere at later times with the normal "developmental program" of the lung. Similarly, delayed onset CNS maturation effects associated with prenatal DEX treatment have recently been discussed in this same vein (38). Not only DEX, but any exogenous agent that either inhibits or stimulates immature (lung) development may serve to alter some facet of later (lung) development or (lung) responses to stressors (37).

Finally, one can speculate on the possible meaning of these experimental newborn animal studies of pulmonary $\mathrm{O}_{2}$ toxicity in relation to the clinical situation. Prenatal glucocorticoid treatment for imminent premature birth may actually have a dual beneficial effect in accelerating fetal lung maturation of both the surfactant and the AOE system. The DEX-treated prematurely born infant would thus have an important antioxidant advantage over those equally premature infants born before DEX treatment could be used.

In this light, two recent clinical reports are of interest. These studies specifically looked at whether prenatal glucocorticoid treatment had any effect on the comparative incidence of BPD in treated versus untreated premature newborns $(39,40)$. Both reports clearly demonstrated a reduced incidence of BPD in relationship to prenatal glucocorticoid therapy, especially in infants of $1000-1500 \mathrm{~g}$ birth weight. Both authors speculate whether surfactant stimulation alone could really account for the reduced incidence of chronic lung disease, suggesting, again, that glucocorticoids may have additional effects on the premature lung including structural changes and diverse biochemical changes, many of which still remain unknown.

Addendum. In view of the large number of reports appearing in the recent pediatric literature about the clinical use of DEX postnatally to try to reduce the incidence and severity of BPD (41-44), it is very important to point out here that DEX treatment appears to act very differently on the course of experimental pulmonary $\mathrm{O}_{2}$ toxicity when it is administered prenatally (present studies) than when it is administered postnatally during the period of high $\mathrm{O}_{2}$ exposure. When used as a treatment agent during hyperoxia, there is very convincing evidence from animal studies in a variety of species that DEX treatment, rather than having a protective effect, in fact tends to markedly accelerate the development of $\mathrm{O}_{2}$-induced lung damage and lethality (31, 45-47). 
Acknowledgments. The author thanks Miguel Martinez for his conscientious technical assistance and Martha Sanchez for her help with the manuscript preparation.

\section{REFERENCES}

1. Zachman RD 1982 The NIH multicenter study and miscellaneous clinica trials of antenatal corticosteroid administration. In: Farrell PM (ed) Lung Development: Biological and Clinical Perspectives. Vol II. Neonatal Respiratory Distress. Academic Press, New York, pp 275-296

2. Frank L, Lewis P, Sosenko IRS 1985 Dexamethasone stimulates fetal rat lung antioxidant enzyme activity in parallel with surfactant stimulation. Pediatrics 75:569-574

3. Frank L, Groseclose EE 1984 Preparation for birth into an $\mathrm{O}_{2}$-rich environment: the antioxidant enzymes in the developing rabbit lung. Pediatr Res 18:240-244

4. Frank L, Sosenko IRS 1987 Development of lung antioxidant enzyme system in late gestation: possible implications for the prematurely-born infant. J Pediatr 110:9-14

5. Frank L, Sosenko IRS 1987 Prenatal development of lung antioxidant enzymes in four species. J Pediatr 110:106-110

6. Tanswell AK, Freeman BA 1984 Pulmonary antioxidant enzyme maturation in the fetal and neonatal rat: I. Developmental profiles. Pediatr Res 18: 584-587

7. Gerdin E, Tyden O, Eriksson UJ 1985 The development of antioxidan enzymatic defense in the perinatal rat lung: activities of superoxide dismutase, glutathione peroxidase, and catalase. Pediatr Res 19:687-691

8. Walther FJ, Wade AB, Warburton D, Forman HJ 1991 Ontogeny of antioxidant enzymes in the fetal lamb lung. Exp Lung Res 17:39-45

9. Dejour P 1981 Principles of Comparative Respiratory Physiology. Elsevier/ North Holland, Amsterdam, pp 147-171

10. McCord JM, Fridovich I 1969 Superoxide dismutase: an enzymic function for erythrocuprein (hemocuprein). J Biol Chem 244:6049-6055

11. Holmes RW, Masters CJ 1970 Epigenetic interconversions of the multiple forms of mouse liver catalase. FEBS Lett 11:45-48

12. Paglia DE, Valentine WN 1967 Studies on the quantitative and qualitative characterization of erythrocyte glutathione peroxidase. J Lab Clin Med 70:158-169

13. Schacterle GR, Pollack RL 1973 A simplified method for the quantitative assay of small amounts of protein in biological material. Anal Biochem 51:654-655

14. Richards GM 1974 Modifications of the diphenylamine reaction giving in creased sensitivity and simplicity in the estimation of DNA. Anal Biochem 57:369-376

15. Bligh EF, Dyer WJ 1959 A rapid method of total lipid extraction and purification. Can J Biochem Physiol 37:911-917

16. Morrison WR 1964 A fast, simple and reliable method for the microdetermination of phosphorus in biological materials. Anal Biochem 11:218-224

17. Mason RJ, Nellebogen J, Clements JA 1976 Isolation of disaturated phosphatidylcholine with osmium tetroxide. J Lipid Res 17:281-284

18. Ward PA, Till GO, Hatherill JR, Annesley TM, Kunkel RG 1985 Systemic complement activation, lung injury, and products of lipid peroxidation. $J$ Clin Invest 76:517-527

19. Naum Y, Morgan TE 1973 A microassay for elastin. Anal Biochem 53: 392-396

20. Frank L 1987 Oxygen toxicity in neonatal rats: the effect of endotoxin treatment on survival during and post- $\mathrm{O}_{2}$ exposure. Pediatr Res 21:109-115

21. Weibel ER, Staubli W, Gnogi HR, Hess FA 1969 Correlated morphometric and biochemical studies on the liver cell. I. Morphometric model, stereological methods and normal morphometric data for rat liver. J Cell Biol 42: 69-91

22. Thurlbeck WM, Galaugher W, Mathers J 1981 Adaptive response to pneumonectomy in puppies. Thorax 36:414-427

23. Steel RGD, Torrie JH 1960 Principles and procedures of statistics. McGrawHill, New York
24. Frank L, Roberts RJ 1979 Effects of low-dose prenatal corticosteroid administration on the premature rat. Biol Neonate 36:1-9

25. Oberg KC, Carpenter G 1989 Dexamethasone acts as a negative regulator of epidermal growth factor receptor synthesis in fetal rat lung cells. Mol Endocrinol 3:915-922

26. Schellhase DE, Shannon JM 1991 Effects of maternal dexamethasone on expression of SP-A, SP-B and SP-C in the fetal rat lung. Am J Respir Cell Mol Biol 4:304-312

27. Boynton BR 1988 The epidemiology of bronchopulmonary dysplasia. In: Merritt JA, Northway Jr WH, Boynton BR (eds) Contemporary Issues in Fetal and Neonatal Medicine. Vol 4. Bronchopulmonary Dysplasia. Blackwell, Cambridge, UK, pp 19-32

28. White CW 1988 Pulmonary oxygen toxicity: cellular mechanisms of oxidant injury and antioxidant defenses. In: Bancalari E, Stocker JT (eds) Bronchopulmonary Dysplasia. Hemisphere, Cambridge, UK, pp 22-41

29. Roberts RJ 1986 Antioxidant systems of the developing lung. In: Farrell PM Taussig LM (eds) Bronchopulmonary Dysplasia and Related Chronic Respiratory Disorders. Ross Labs, Columbus, OH, pp 24-32

30. Autor AP, Frank L, Roberts RJ 1976 Developmental characteristics of pulmonary superoxide dismutase: relationship to idiopathic respiratory distress syndrome. Pediatr Res 10:154-158

31. Frank L 1991 Developmental aspects of experimental pulmonary oxygen toxicity. Free Rad Biol Med 11:463-494

32. Zweir JL, Duke SS, Kuppusamy P, Sylvester JT, Gabrielson EW 1989 Electron paramagnetic resonance evidence that cellular oxygen toxicity is caused by generation of superoxide and hydroxyl free radicals. FEBS Lett 252:12-16

33. Freeman BA, Crapo JD 1981 Hyperoxia increases oxygen free radical production in rat lung and lung mitochondria. J Biol Chem 256:10986-10992

34. Yusa T, Crapo JD, Freeman BA 1984 Hyperoxia enhances lung and liver nuclear superoxide generation. Biochim Biophys Acta 793:167-174

35. Chevion M 1988 A site-specific mechanism for free radical induced biological damage: the essential role of redox-active transition metals. Free Rad Bio Med 5:27-37

36. Schellenberg J-C, Liggins GC, Stewart AW 1987 Growth, elastin concentration, and collagen concentration of perinatal rat lung: effects of dexamethasone. Pediatr Res 21:603-607

37. Davies P, Reid L 1982 Developmental constraints in compensatory postnatal growth of the lung. J Dev Physiol 4:265-272

38. Carlos RQ, Seidler FJ, Lappi SE, Slotkin TA 1991 Fetal dexamethasone exposure affects basal ornithine decarboxylase activity in developing rat brain regions and alters acute responses to hypoxia and maternal separation. Biol Neonate 59:69-77

39. Van Marter LJ, Leviton A, Kuban KCK, Pagano M, Allred EN 1990 Materna glucocorticoid therapy and reduced risk of bronchopulmonary dysplasia. Pediatrics 86:331-336

40. Doyle L, Kitchen W, Ford G, Rickards AL, Lissenden JV, Ryan MM 1986 Effects of antenatal steroid therapy on mortality and morbidity in very low birth weight infants. J Pediatr 108:287-292

41. Kazzi NJ, Brans YW, Poland RL 1990 Dexamethasone effects on the hospita course of infants with bronchopulmonary dysplasia who are dependent on artificial ventilation. Pediatrics 86:722-727

42. Cummings JJ, D'Eugenio DB, Gross SJ 1989 A controlled trial of dexamethasone in preterm infants at high risk of bronchopulmonary dysplasia. N Engl J Med 320:1505-1510

43. Ferrara TB, Couser RJ, Hoekstra RE 1990 Side effects and long-term followup of corticosteroid therapy in very low birthweight infants with bronchopulmonary dysplasia. J Perinatol 10:137-142

44. Merz U, Kuehl G, Linderkamp O 1989 Dexamethasone therapy in bronchopulmonary dysplasia. Klin Pediatr 201:11-15

45. Newman JH, Fulkerson WJ, Kobayashi T, English D, Meyrick B, Brigham KL 1986 Effects of methylprednisolone on lung oxygen toxicity in awake sheep. J Appl Physiol 60:1386-1392

46. Halpern P, Teitelman U, Lanir A 1986 Effects of methylprednisolone on normobaric pulmonary oxygen toxicity in rats. Respiration 48:153-158

47. Ohtsu N, Ariagno RL, Sweeney TE, Davis L, Moses L, Petriceks R, Daehne I, Bensch K, Northway Jr WH 1989 The effect of dexamethasone on chronic pulmonary oxygen toxicity in infant mice. Pediatr Res 25:353-359 